\title{
Mechanical Properties of Phormium Tenax Reinforced Natural Rubber Composites
}

\author{
Sivasubramanian Palanisamy ${ }^{1}\left(\mathbb{D}\right.$, Kalimuthu Mayandi $^{1}{ }^{(0)}$, Murugesan Palaniappan ${ }^{2}$, Azeez Alavudeen ${ }^{1}$, \\ Nagarajan Rajini ${ }^{1}\left[{ }^{(1)}\right.$, Felipe Vannucchi de Camargo ${ }^{3}(\mathbb{D})$ and Carlo Santulli ${ }^{4, *}$
}

1 Department of Mechanical Engineering, Kalasalingam Academy of Research and Education, Anand Nagar, Krishnankovil, Srivilliputhur, Tamil Nadu 626128, India; sivaresearch948@gmail.com (S.P.); k.mayandi@gmail.com (K.M.); alacomposite@gmail.com (A.A.); rajiniklu@gmail.com (N.R.)

2 Department of Mechanical Engineering, College of Engineering, Al-Imam Mohammed Ibn Saud Islamic University, Riyadh 11432, Saudi Arabia; mpapathi@imamu.edu.sa

3 Post-Graduation Program in Mining, Metallurgical and Materials Engineering, Federal University of Rio Grande do Sul, Porto Alegre 90035-190, Brazil; felipe.vannucchi@ufrgs.br

4 School of Science and Technology, Geology Section, Università di Camerino, 62032 Camerino, Italy

* Correspondence: carlo.santulli@unicam.it; Tel.: +39-380-6522232

Citation: Palanisamy, S.; Mayandi, K.; Palaniappan, M.; Alavudeen, A.; Rajini, N.; Vannucchi de Camargo, F.; Santulli, C. Mechanical Properties of Phormium Tenax Reinforced Natural Rubber Composites. Fibers 2021, 9, 11 https://doi.org/10.3390/fib9020011

Received: 27 November 2020

Accepted: 11 January 2021

Published: 1 February 2021

Publisher's Note: MDPI stays neutral with regard to jurisdictional clai$\mathrm{ms}$ in published maps and institutional affiliations.

Copyright: (C) 2021 by the authors. Licensee MDPI, Basel, Switzerland. This article is an open access article distributed under the terms and conditions of the Creative Commons Attribution (CC BY) license (https:// creativecommons.org/licenses/by/ $4.0 /)$.

\begin{abstract}
The introduction of natural fibers as a filler in a natural rubber (NR) matrix can be of relevance for their eco-friendly and sustainable nature as the substitute for carbon-based fillers. In this work, short Phormium tenax fibers were introduced in random orientation into a NR matrix in different lengths $(6,10$, and $14 \mathrm{~mm})$ and various amounts $(10,20$, and 30\%, taking 100 as the NR weight). The composite was fabricated using a two-roll mill according to American Society for Testing and Materials (ASTM) D3184-11 standard. Several properties were determined, namely tensile and tear characteristics, hardness, and abrasion resistance. The results suggest that the shortest fiber length used, $6 \mathrm{~mm}$, offered the best combination between loss of mechanical (tensile and tear) properties and hardness and the most acceptable resistance to abrasion, with the properties increasing with the amount of fibers present in NR. As a consequence, it is indicated that a higher amount of fibers could be possibly introduced, especially to achieve harder composites, though this would require a more controlled mixing process not excessively reducing tensile elongation at break.
\end{abstract}

Keywords: abrasion; fiber length; hardness; mechanical properties; rubber composite; untreated Phormium tenax

\section{Introduction}

Natural fibers (NF) are fibers that are produced by plants (as flax, hemp, and cotton), animals (as silk and wood), and even geological processes (as basalt). They can be used as a reinforced component in composite materials [1,2] and are often conceptually considered in opposition to the most common technological fibers (such as carbon, glass, and Kevlar) $[3,4]$ because they offer an undisputed advantage in term of eco-sustainability [5-7]. However, given that their mechanical properties are not always excellent, it is in the integration ("hybridization") between natural and technological fibers that the best successes in terms of application have been achieved today [8-10]. This happens for composites based on polymer resins, such as polyester and vinyl ester, with a huge number of investigations that show the positive effects offered by the natural fibers [11,12].

Less studied is the effect of the introduction of natural fibers in natural rubber. In fact, the use of natural fibers to serve as a reinforcement of natural rubber has received some attention lately, in particular to provide hardening and to reduce the use of fillers such as carbon black, which are traditionally used to improve the usefulness of rubber for practical purposes [13]. A substitution with natural fibers does influence the mechanical properties of rubber-based material, in particular tensile and tear properties and abrasion resistance. Though they might not be as effective as carbon-based fillers, an additional advantage 
of natural fibers is their low cost, sustainability, and the possibility to obtain them using by-products or even post-harvest or pruning waste from agricultural productive systems.

A number of attempts have been carried out to fabricate rubber composites using natural fibers, typically in the form of short chopped fibers, a possibility that is sustainable also because rubber may become a suitable matrix for the introduction of crop waste with good mechanical performance [14]. A study on the introduction of 6-mm-long sisal and oil palm fibers in natural rubber indicated a reduction of tensile and tear strength compensated by an increase in modulus at $100 \%$ stress, growing with the amount of fibers introduced [15]. The introduction of jute fiber at $10 \mathrm{~mm}$ produced similar results, indicating even a positive effect on natural rubber strain, up to $40 \%$ jute fibers over 100 parts of rubber [16]. On the other hand, it is also possible that the introduction of very short fibers, as done in the case of coir, and the viscous losses of natural rubber would even increase with the introduction of fibers [17]. Natural fibers can be treated prior to introduction into natural rubber, for example, using chemical treatments, such as alkali-based ones: for example, in the case of pineapple leaf fibers (PALF), this resulted in a very limited advantage in terms of mechanical performance over the untreated fibers [18].

These studies created a number of questions related to the introduction of natural fibers into rubber. One of the main issues is the minimal length of fiber that can produce some positive effect on the composite and, hence, the assessment of critical length: in [17], e.g., a length of $10 \mathrm{~mm}$ was purposely applied on coir in the understanding that this would be considerably higher than the critical length. However, the use of a rolling mill, required for the introduction of fibers into rubber, obviously resulted in a reduction of the size of the fibers; therefore, it is important that the mechanical effect is maintained even after milling using a suitable fiber length [19]. An issue in the application of natural fibers is the variable presence of voids and the irregular geometry of their section, which results in difficult evaluation of their effective diameter and therefore of their length/diameter ratio, usually referred to as "aspect ratio". Despite this, in principle, a higher aspect ratio would be desirable to enhance the performance of the composite, while on the other hand, it is well known that longer fibers may tend to bend and curl during processing [20]. Controlling this aspect is also significant because the expectation is that the increase in hardness of rubber obtained by the addition of natural fibers would not affect the occurrence of strain-induced crystallization (SIC) [21].

In the specific case of phormium tenax, these fibers are separated from the leaves of the plant that, though diffused as a gardening shrub in a large part of the world, is a monocotyledonous native of New Zealand, offering fibers, identified as Harakeke, historically used by Maori people to weave ropes and mats [22]. Phormium fibers contain a substantial amount of cellulose, which offers the possibility to obtain quite flexible yet resistant fibers: more specifically, their composition appeared to be $60.9( \pm 4.4) \%$ cellulose, $27.3( \pm 4.1) \%$ hemicellulose, and $7.8( \pm 1.3) \%$ lignin, with $4.0( \pm 0.3) \%$ extractives [23]. This allowed the extraction of nanocellulose crystals by mechanical disintegration of the fiber [24].

It was also demonstrated that phormium fibers offer a sufficient tensile strength to be proposed for application in composites as a randomly oriented reinforcement [25]. More specifically, in the best cases, despite possible inaccuracies in diameter measurements, a tensile strength in the order of 1 GPa was obtained for phormium fibers [26]. It is no surprise therefore that phormium fibers at different lengths and amounts have been proposed as the filler for traditional oil-derived thermosetting matrices, such as epoxy $[27,28]$, suggesting that the resin was able to offer a sufficient grip with the reinforcement by penetrating the fiber bundles [29]. Studies were performed also with thermoplastic matrices, both non-biodegradable, such as polypropylene [30], and biodegradable, such as poly (lactic acid) [31]. In all the above cases, despite their non-negligible geometrical variability, phormium fiber offered some potential. This work concentrates on the possibility to apply these fibers in different amounts and cut to different lengths as the filler for a natural rubber composite, a possibility that has received little attention so far. The scope 
of this introduction of these fibers into rubber composites encompasses increasing the material hardness with sustainable, low cost, and low weight filler: as previously observed in the case of the introduction of jute fibers [32], this is likely to result in other problems, such as some reduction of mechanical, in particular tensile, performance. The experimental program followed aims to observe the influence of fiber length and content on the balance between these properties to lead to possible application.

\section{Materials and Methods}

\subsection{Phormium Tenax Fibers}

Phormium leaves were collected in the fields around Tamilnadu, India. After collection and cutting close to the root, which gave leaves between 0 and $80 \mathrm{~cm}$ long, they were immersed straight in a container of water with a capacity of $20 \mathrm{~L}$, which was filled with tap water for 30-40 days. The leaves were not exposed to sunlight, rain, or wind during the period to reduce the variability of fiber properties. Water was often added to maintain its level. The leaves were regularly observed. The fibers were then separated from the leaf by stripping: as a whole, they represent over $70 \%$ of the weight of the whole leaf, the remainder weight being due to loose parts and protective waxes. The fibers were then washed again while combing under running water (to avoid the formation of knots on the fibers) and finally dried for a few hours under sunlight. The initial appearance of the leaves is reported in Figure 1a, and the final appearance of the fibrous material is reported in Figure 1b. Once ready, the fibers were cut into measured lengths of 6, 10, and $14 \mathrm{~mm}$ using scissors, with a measured accuracy of $\pm 0.1 \mathrm{~mm}$. Some of these fibers were collected to be observed under an optical microscope to evaluate their morphology.
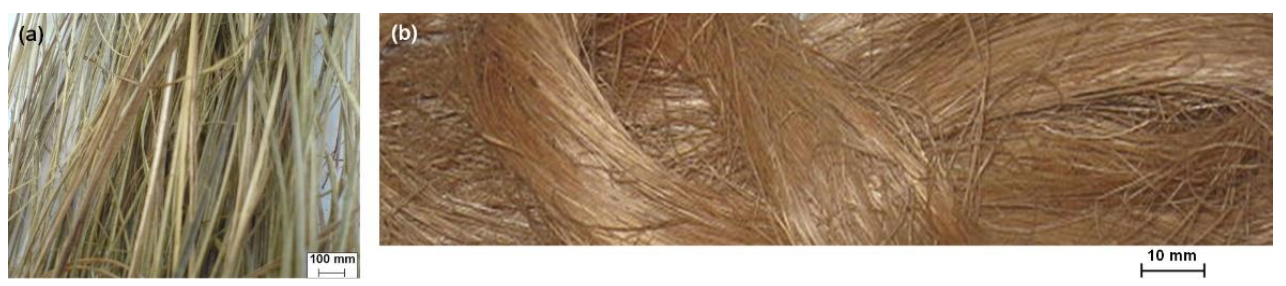

Figure 1. Phormium fiber extraction: (a) initial appearance of the leaves and (b) appearance of the fibrous material after stripping.

\subsection{Natural Rubber and Rubber Composites Formulation}

Natural rubber was provided by the Rubber Research Institute of India (RRII), Puthupally, Kottayam. The chemicals listed in Table 1, all of commercial grade, were supplied by NICE Chemicals Pvt Ltd., Manimala Rd, Ponekkara, Edappally, Ernakulam, Kerala 682024, India, except CBS (N-cyclohexyl-2-benzothiazolesulfenamide) and TMQ (poly(1,2-dihydro2,2,4-trimethylquinoline)), which were provided by Spectrum Reagents and Chemicals Pvt Ltd., VI/575-A Idabinanipuram Poedayar 676KL, 683502 Cochin, India, and were utilized to fabricate the natural rubber/phormium leaf fiber composite. The application of the quite high amount of sulfur, $2.5 \mathrm{wt} . \%$, and no industrial accelerators, such as Tetramethylthiuram Disulfide (TMTD), resulted in a compound for conventional vulcanization at quite high temperature $\left(150{ }^{\circ} \mathrm{C}\right)$. It can be therefore expected that the vulcanizate would contain mostly polysulphidic crosslinks with a relatively high level of chain modification [33]. Also, the absence of carbon black (CB) should result in a Shore A hardness much lower than for CB-filled rubber. 
Table 1. Chemicals used for rubber composite production (given per 100 parts natural rubber).

\begin{tabular}{ccccc}
\hline Ingredient & NR & P1 & P2 & P3 \\
\hline $\begin{array}{c}\text { Natural rubber } \\
\text { Stearic acid }\end{array}$ & 100 & 100 & 100 & 100 \\
$\begin{array}{c}\text { Zinc oxide } \\
\text { poly(1,2-dihydro-2,2,4- } \\
\text { trimethylquinoline) } \\
\quad(\text { TMQ) }\end{array}$ & 2 & 2 & 2 & 2 \\
$\quad \begin{array}{c}\text { N-cyclohexyl-2- } \\
\text { benzothiazolesulfenamide } \\
\quad(\text { CBS) }\end{array}$ & 1 & 5 & 5 & 5 \\
$\quad$ Sulfur & 0.8 & 0.8 & 0.8 & \\
$\begin{array}{c}\text { Untreated Phormium } \\
\text { tenax fiber }\end{array}$ & 2.5 & 2.5 & 2.5 & 2.5 \\
\hline
\end{tabular}

The objective was to produce six types of composites, named NR, P1, P2-6, P2-10, P2-14, and P3. NR did not include any phormium fibers, serving as a control sample; P1 and P3 were all filled with 6-mm-long phormium fibers; whilst P2-6, P2-10, and P2-14 were filled with $6 \mathrm{~mm}, 10 \mathrm{~mm}$, and $14 \mathrm{~mm}$ phormium fibers, respectively. The amount of phormium fibers introduced grew, passing from P1 and P2 to P3, with the idea to introduce 10,20 , and 30 parts fiber per 100 parts natural rubber alone. As a whole, even excluding stearic acid, which can be obtained not only chemically, as the one used here, but also from animal and plant fat, this represented the amount of bio-based materials (natural fibers + phormium fibers) that varied between 90 and $92 \mathrm{wt} . \%$.

\subsection{Rubber Composite Fabrication}

Composite materials were prepared by using a two-roll mill $(150 \times 300 \mathrm{~mm}) \mathrm{IND}$ EXPELL Model no. IEW/M-1 at ambient temperature with 1:1.25 frictional ratio under American Society for Testing and Materials (ASTM) D 3184-11 standard. The characteristics of the two-roll mills were roller diameter $=150 \mathrm{~mm}$, face width $=300 \mathrm{~mm}$, motor $=7.5 \mathrm{HP}$, $1440 \mathrm{rpm}$, batch capacity $=3 \mathrm{~kg}$, and reduction gear ratio $=40: 1$. The necessary quantities were added into a mill opening of $1.5 \mathrm{~mm}$. The values were selected to increase the fiber orientation in the mill direction. The natural rubber was masticated in the mill for a few minutes, after which the ingredients were added. The fibers were mixed thoroughly and added to the end of the mixture, taking care to maintain the direction of the flow of the compound, so the majority of the fibers followed the direction of flow. This is a procedure that was necessary to not excessively fragment the fibers during mastication [34]. Later, after completed mixing, the rolled sheet was pulled out through a $0.8-\mathrm{mm}$ tightly fixed nip gap at the end of the lap six times and finally left at a 3-mm nip gap. The other composition parameters, like mill/roll speed ratio and temperature, were similar for all sets of observations. The aspects of the compound, as that from Figure 2, reported a non negligible thickness variation, which will likely represent a problem when dealing with natural fiber introduction, such as phormium, which are dimensionally variable as well in nature. The compounds for their respective optimum curing times $t_{90}$, reported in Table 2, together with other parameters for curing, obtained using the oscillating disc rheometer (ODR) test, were vulcanized to $150{ }^{\circ} \mathrm{C}$ with hydraulic pressure, as detailed below. It is noteworthy that no particular and clear influence of the fiber length and quantity is noticed, so these parameters are only reported for completeness. Due to the method purposely adopted, pre-vulcanization of sulfur is likely to occur; therefore, mixing of the compound did not exceed around 2-3 min, slightly depending of course on the amount of phormium fiber introduced. 


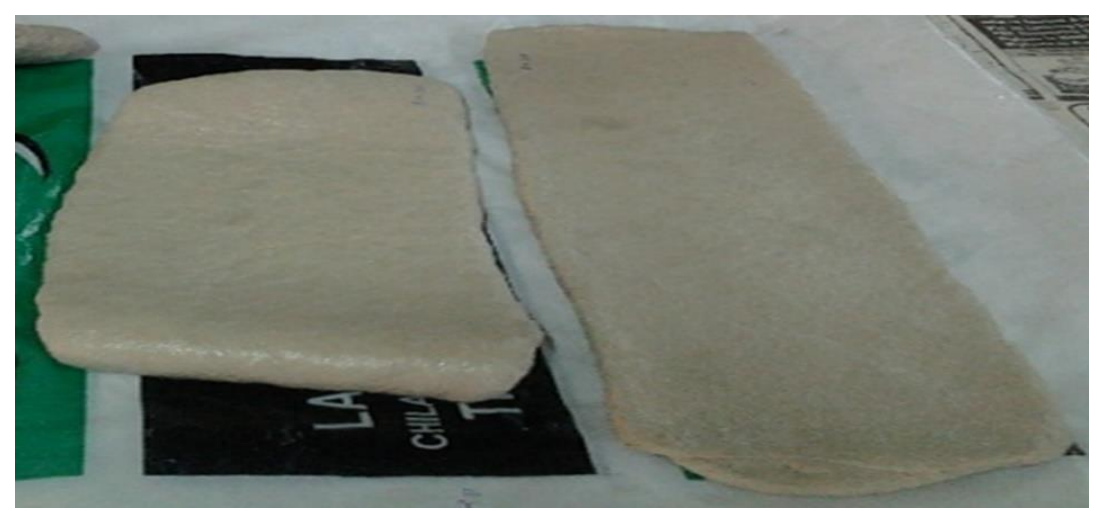

Figure 2. Aspect of the compound before curing.

Table 2. Curing characteristics for the different composites.

\begin{tabular}{ccccccc}
\hline & NR & P1 & P2-6 & P2-10 & P2-14 & P3 \\
\hline $\begin{array}{c}\text { Min. } \\
\text { Torque } \\
\left(\mathrm{N}^{*} \mathrm{~m}\right)\end{array}$ & 0.01 & 0.04 & 0.06 & 0.04 & 0.03 & 0.08 \\
$\begin{array}{c}\text { Max. } \\
\text { Torque } \\
\left(\mathrm{N}^{*} \mathrm{~m}\right)\end{array}$ & 0.26 & 0.34 & 0.8 & 0.41 & 0.28 & 0.73 \\
$\begin{array}{c}\text { Scorch } \\
\text { time Ts }(2) \\
(\mathrm{min})\end{array}$ & 1.87 & 2.17 & 3.74 & 2.11 & 2.83 & 3.04 \\
$\begin{array}{c}\text { Cure time } \\
\text { at } 150^{\circ} \mathrm{C} \\
(\mathrm{min})\end{array}$ & 4.5 & 7.1 & 10.1 & 6.5 & 7.5 & 9.1 \\
\hline
\end{tabular}

\subsection{Molding of the Test Specimens}

The test specimens to determine the physical properties (tensile, tear, hardness, and abrasion) were prepared in unheated molds by compression molding on electrically heated hydraulic press plates with approximately $450-\mathrm{mm}$ sides at a pressure of $200 \mathrm{~kg} / \mathrm{cm}^{2}$ with $2.5( \pm 0.2) \mathrm{mm}$ thickness. The rubber compounds were vulcanized at $150{ }^{\circ} \mathrm{C}$, and the molded material was immediately cooled in running water, kept in the cold and dark for $24 \mathrm{~h}$, and used for subsequent physical tests.

\subsection{Characterization Tests}

\subsubsection{Tensile Tests}

A stress-strain curve measurement was obtained on a Shimatsu Model AG1 universal testing machine, setting a cross-head speed of $500 \mathrm{~mm} / \mathrm{min}$ as suitable for pure rubber. The tensile strength, tensile modulus, and elongation at break were calculated according to ASTM D 412-87 (method A). From the molded rubber sheets, samples were cut in the grain direction in a dumb-bell shape with a total length of $100 \mathrm{~mm}$, a grip length of $33 \mathrm{~mm}$, and a width of $16 \mathrm{~mm}$ at both ends, reduced at $3 \mathrm{~mm}$ along the grip length. Each test sample was clamped to the grip of the tensometer. Then, applied stress, load, and elongation at the break were noted, so that the tensile strength in $\mathrm{MPa}$ and the percentage of elongation at the break is also reportable. Five samples per category were tested.

\subsubsection{Tear Tests}

Tear strength was measured using crescent-shaped test samples (length $100 \mathrm{~mm}$ and angle of $90^{\circ}$ ), according to ASTM D624-86, using a Shimatsu Model AG1 at a universal testing machine with a cross-head speed of $500 \mathrm{~mm} / \mathrm{min}$. The samples were prepared from molded rubber sheets along with mill grain direction. The tear strength was reported in $\mathrm{kN} / \mathrm{m}$. Five samples per category were tested. 


\subsubsection{Hardness}

According to ASTM 2240-81, the composite hardness strength was determined by a Shore A-type durometer using circular samples with 40-mm diameter. The measured spring provided the inductive force using the tensioning instrument. The load imposed by the spring varied with indentation. When the specimen was in contact with the sample, an indentation force was applied for $15 \mathrm{~s}$, after which the reading was taken.

\subsubsection{Abrasion Resistance}

Abrasion testing was performed by a DIN abrader. According to DIN 53516, a cylindrical specimen of 16-mm diameter and 10-mm height was put into contact with the abrasive surface of a drum rotating at $40 \mathrm{rpm}$, subjecting the sample to a 1-N load. When the abrasive direction constantly changed with the rotation of the specimen on its axis, it was abrasive. Then, after completing the abrasive path, the sample was weighed by 0.001 balancing tools. Abrasion was defined as a measurement of cubic centimeters abraded during a $1 \mathrm{~h}$ test.

\section{Results and Discussion}

The phormium fiber morphology is observed in Figure 3 from the optical microscopy transverse observation of their cross sections, along the lines of the method suggested in [35]. The images suggest that their typical structure is as a collection of polygonal cells, for which the shape is not far removed from the quasi-hexagonal section characteristic of flax fibers [36]. Four shapes are tentatively identified, also based on previous studies [37]: elongated, quasi circular, horseshoe, and keyhole. In all of these, the presence of lumens appears to represent a considerable portion of the whole section. This, added to the fact that most fibers have a section with quite distant geometry from a circular one, suggests the significance of possible errors in the evaluation of the tensile strength of the composite.
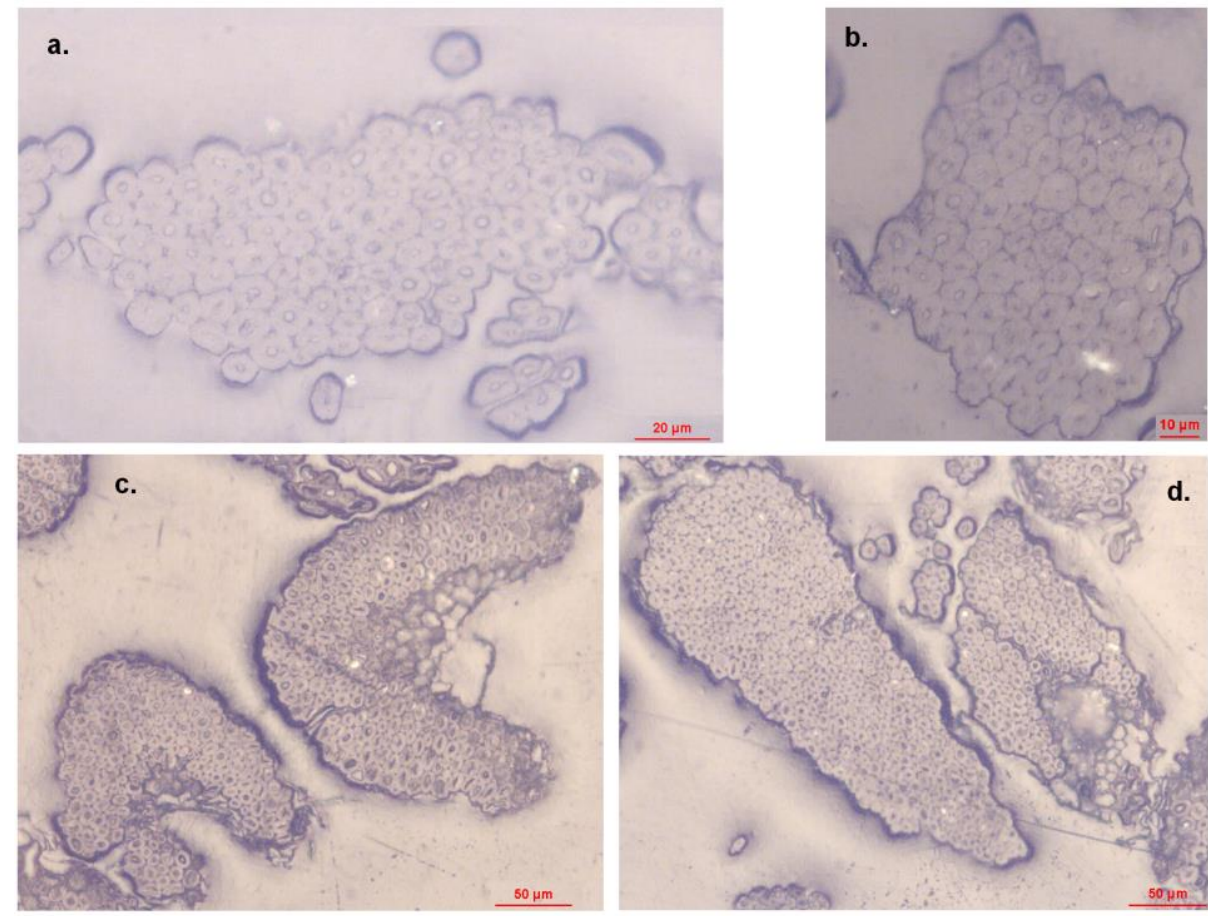

Figure 3. Different geometries of phormium fibers: (a) elongated, (b) quasi-circular, (c) keyhole, and (d) horseshoe.

Another source of possible inaccuracy is given by the fact that, during processing of the rubber composite, phormium fibers are broken by the effect of rolling mills due to the fact that shear force takes place when mixing most of the fiber in the direction of the mill 
grain. A number of factors influence it, such as the initial rate of damage, the magnitude of stress and strain, and obviously the type of fiber. The fiber diameter hardly changes during processing, especially if the natural fiber is sufficiently hard [38]. The results on fiber breakage are reported in Figure 4, which indicate that, of the three fiber lengths used, the shortest one, $6 \mathrm{~mm}$, suffered the least fragmentation whilst the longest one, $14 \mathrm{~mm}$, was basically always reduced in length by processing. For this reason, verification in a subsequent experimental work was suggested to examine whether it was possible to increase the amount of 6-mm fibers introduced in the composites or if the advantage obtained from using longer fibers would justify a future intervention on processing to make it more suitable for the introduction of phormium fibers.

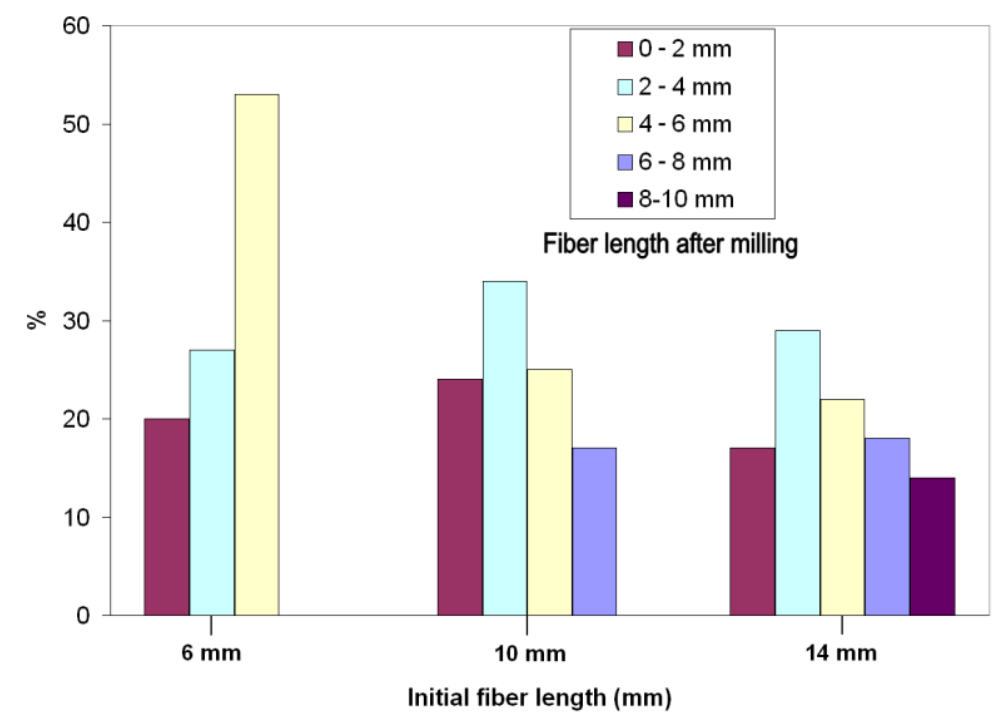

Figure 4. Analysis over fiber breakage (after mixing).

Passing to tensile performance, Figure 5, which reports typical curves obtained for the six series of specimens, illustrates that, in all cases, a considerable decrease of tensile strength is obtained with respect to pure rubber. It is also likely that strain-induced crystallization (SIC), which can produce an increase in stress above a certain deformation level, would be equally reduced. This would take place as the effect of the disruption produced in the structure of rubber molecules by the introduction of phormium fibers. This phenomenon is also attributed to the attraction between the polymer molecules and the filler, as it is normally observed in natural rubber fiber composites [39]. However, the dimensional variability of the phormium fibers also results in a higher difficulty posed by the matrix sliding with respect to the fibers once the strain produces an onset of defects at the interface.

Another possible suggestion is that the occurrence of SIC would confer to the rubber more strength at lower strains, as verified with pineapple leaf fibers [40]. The virtual absence of an increase of stress at higher strains, therefore resulting in a "flatter" curve, is especially encountered in the case of the P2-6 and P3 curves, when more than $10 \%$ of 6-mm-long fibers were added. On the other hand, the notably high elongation typically offered when introducing 14-mm-long fibers in the matrix may indicate that the capacity to bend and generally curve longer fibers is possibly beneficial when obtaining a higher strain.

A sounder analysis of the tensile test results over the whole set of samples, reported in Figure 6, suggests again that the best option for tensile performance is introducing a small amount of short phormium fibers, although in all cases, the loss in terms of strength appears significant. 


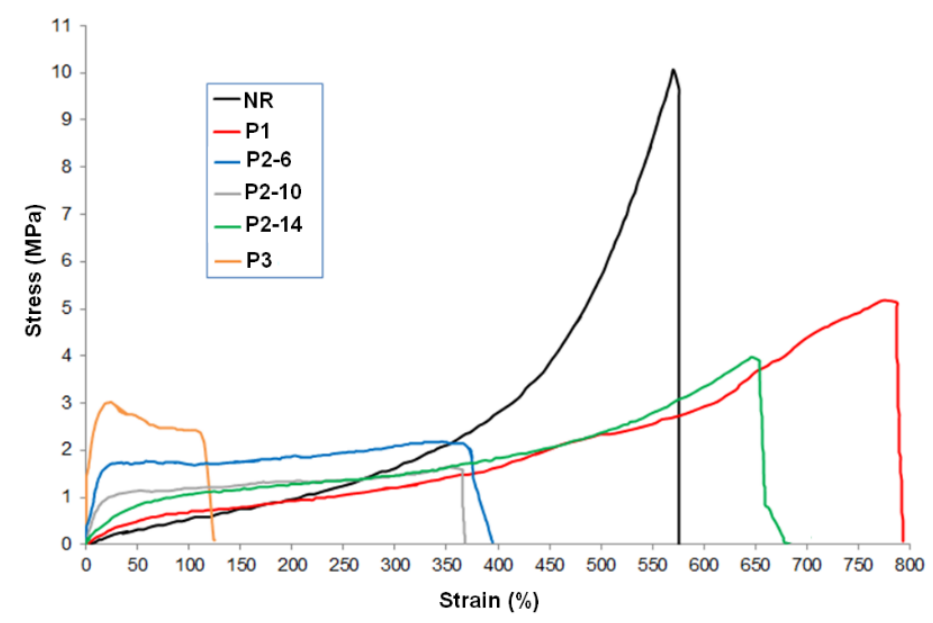

Figure 5. Typical tensile curves for different categories of samples.

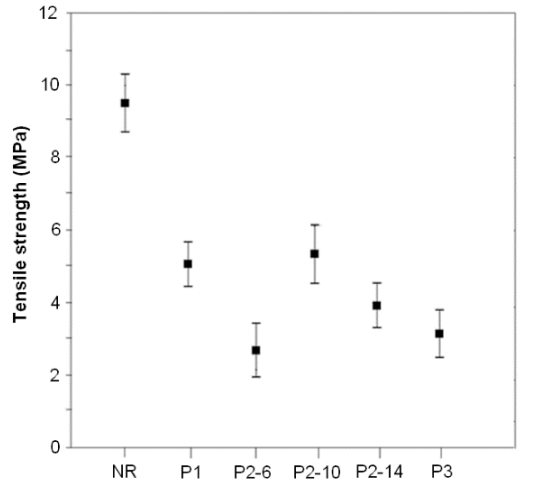

(a)

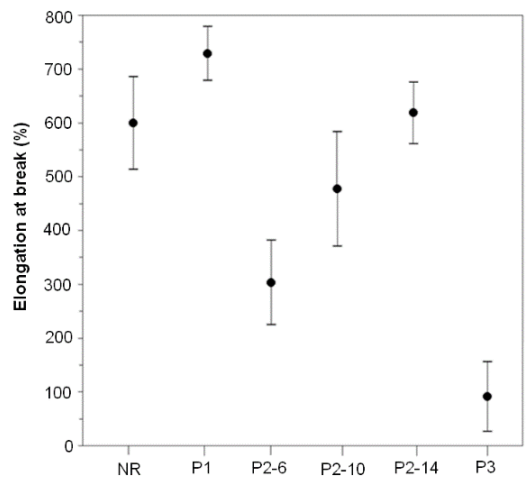

(b)

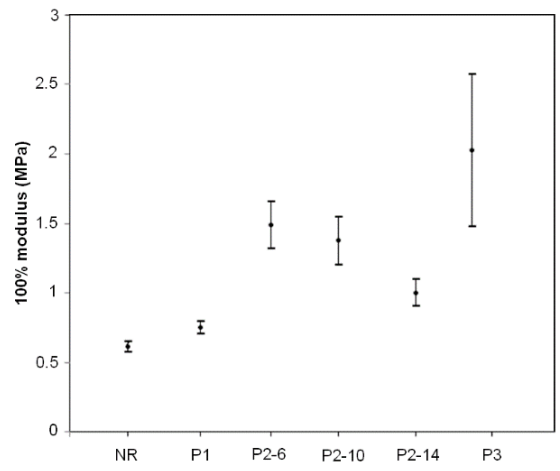

(c)

Figure 6. Tensile properties of the different rubber matrix composites: (a) tensile strength (MPa) (average and standard deviation), (b) elongation at break (\%) (average and standard deviation), and (c) 100\% modulus (MPa) (average and standard deviation).

In particular, in terms of tensile strength (Figure 6a), the only option comparable with pure natural rubber is inserting $10 \%$ of 6 -mm-long phormium fibers (P1): this composite is also the one that bears considerable elongation, higher than that of pure natural rubber itself (Figure 6b). The possibility to increase the amount of fibers introduced for a higher stiffness also appears to be of interest: however, this considerably reduces elongation of the composite to the point that, with the introduction of $30 \%$ of $6-\mathrm{mm}$-long fibers (P3), strain-induced crystallization is affected, so that, in some cases, even $100 \%$ deformation is not reached before rupture. As a consequence, the higher stiffness is only reached with considerable scattering of values and, therefore, limited predictability of the behavior 
(Figure 6c). This effect can be correlated possibly by the scarcely effective stress transfer across the interface between fibers and matrix, probably due also to the irregular and variable surface grip of phormium fibers. On the other hand, using longer fibers (10 or 14 $\mathrm{mm})$ does gradually decrease the modulus with respect to the same amount $(20 \%)$ of 6 mm-long fibers, as can be seen by comparing the performance of the P2-6, P2-10, and P2-14 composites: it may be suggested that it is difficult to maintain the straight alignment of phormium fibers at higher lengths.

In the case of tear strength, as observed in Figure 7a, it is also possible to consider that higher amounts of 6-mm fibers can also be beneficial in delaying tear fracture, although possibly making the performance less controllable. In the same way, since indentation during hardness tests produces distinct tear effects [41], the same effect was revealed (Figure $7 \mathrm{~b}$ ), which suggests the opportunity for the possible introduction of larger quantities of short fibers, although it will make processing more difficult and curing times longer. Another possible criticality in increasing fiber content is shown when dealing with abrasion resistance, measured in $\mathrm{cm}^{3} / \mathrm{h}$, similar to that from other studies on rubber, e.g., [42,43]. Here, no real benefits appear when trebling the amount of 6-mm-long fibers in the composite from P1 to P3 (Figure 7c). A suggestion for this behavior can be possibly linked to the fact that the larger presence of phormium fibers may also result in their agglomeration, if not the formation of complex entanglements, in the composite: this is frequently observed in fibers with high cellulose content [44]. The average results from all mechanical tests are summarized in Table 3.

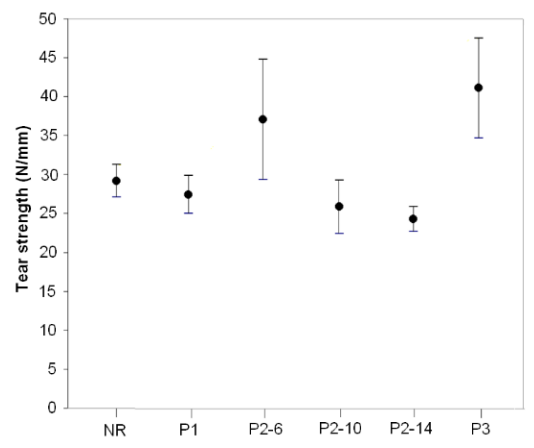

(a)

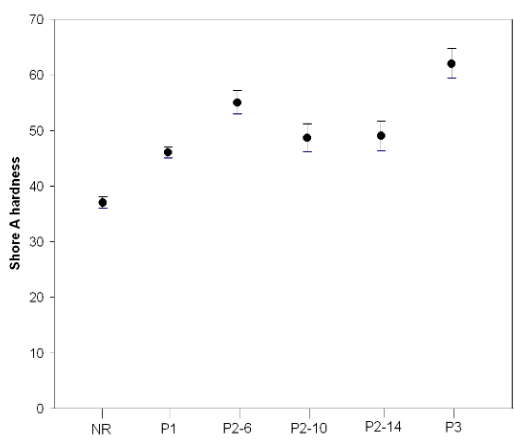

(b)

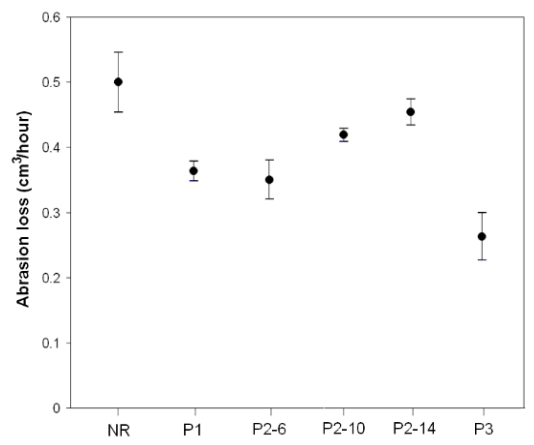

(c)

Figure 7. Other properties of the different rubber matrix composites: (a) tear strength (N/mm) (average and standard deviation), (b) Shore A hardness (average and standard deviation), and (c) abrasion loss $\left(\mathrm{cm}^{3} / \mathrm{h}\right)$ (average and standard deviation). 
Table 3. Summary of the mechanical results (avg. values) of all rubber matrix composites.

\begin{tabular}{|c|c|c|c|c|c|c|}
\hline Properties & NR & P1 & P2-6 & P2-10 & P2-14 & P3 \\
\hline $\begin{array}{c}\text { Tensile strength } \\
(\mathrm{MPa})\end{array}$ & 9.51 & 5.06 & 2.53 & 5.22 & 3.92 & 2.83 \\
\hline Tensile strain (\%) & 600 & 727 & 303 & 536 & 619 & 95 \\
\hline $\begin{array}{l}100 \% \text { modulus } \\
(\mathrm{MPa})\end{array}$ & 0.57 & 0.75 & 1.48 & 1.33 & 0.98 & -1 \\
\hline $\begin{array}{l}200 \% \text { modulus } \\
(\mathrm{MPa})\end{array}$ & 0.98 & 0.78 & 1.54 & 1.24 & 1.13 & -1 \\
\hline $\begin{array}{l}300 \% \text { modulus } \\
(\mathrm{MPa})\end{array}$ & 1.45 & 0.96 & 1.80 & 1.27 & 1.30 & -1 \\
\hline $\begin{array}{l}\text { Tear strength } \\
(\mathrm{N} / \mathrm{mm})\end{array}$ & 29.2 & 27.5 & 37.2 & 26 & 24.4 & 41.2 \\
\hline Shore A hardness & 37 & 46 & 55 & 49 & 49 & 62 \\
\hline Abrasion loss $(\mathrm{cc} / \mathrm{h})$ & 0.5 & 0.36 & 0.35 & 0.42 & 0.45 & 0.26 \\
\hline
\end{tabular}

${ }^{1}$ Not reached by all the samples ( 3 out of five for $100 \%$ and none for $200 \%$ and above).

Some discussion is also reported to compare the tensile results on which there is more literature available, with composites including other natural fibers in similar amounts. Observations that can be drawn from a tentative comparison with the studies in [13,45-48], as reported in Table 4, suggest that, in general terms, a number of natural fibers are able to preserve high elongation in rubber due to strain-induced crystallization. In terms of stiffness and strength, phormium does not always compare favorably, which can be again ascribed to its irregularity with respect to typical textile fibers, such as jute, hemp, or sisal. On the other hand, it is a fiber widely available that grows easily as a weed and that needs to be often disposed of for gardening and maintenance purposes.

Table 4. Comparison between some tensile results of this and other studies.

\begin{tabular}{|c|c|c|c|c|c|c|}
\hline Fiber & $\begin{array}{c}\text { Weight } \\
(\%)\end{array}$ & $\begin{array}{l}\text { Length } \\
(\mathrm{mm})\end{array}$ & $\begin{array}{c}100 \% \\
\text { Modulus } \\
(\mathrm{MPa})\end{array}$ & $\begin{array}{c}\text { Tensile } \\
\text { Strength } \\
\text { (MPa) }\end{array}$ & $\begin{array}{c}\text { Tensile } \\
\text { Strain (\%) }\end{array}$ & Reference \\
\hline Jute & 10 & 10 & 1.9 & 8.9 & 927.9 & [16] \\
\hline $\begin{array}{l}\text { Sisal/oil } \\
\text { palm }\end{array}$ & $\begin{array}{c}\text { Sisal } 21 \\
\text { Oil palm } 9\end{array}$ & $\begin{array}{c}\text { Sisal } 10 \\
\text { Oil palm } 6\end{array}$ & 2.23 & 8.3 & 794 & [43] \\
\hline Banana & 10 & 10 & - & 4.0 & - & [44] \\
\hline $\begin{array}{l}\text { Bowstring } \\
\text { hemp }\end{array}$ & 10 & Nanometric & 2.58 & 13.09 & 605.1 & [45] \\
\hline Hemp & 10 & 3 & 0.85 & 3 & 740 & [46] \\
\hline Phormium & 10 & 6 & 0.75 & 5.06 & 727.4 & This study \\
\hline
\end{tabular}

\section{Conclusions}

The present study aims to develop eco-friendly composite material specimens developed from an analysis of mechanical properties. The biodegradable composite specimen of this study is the fabricated composite by phormium tenax fiber along with natural rubber. The properties of the specimen were compared with different lengths and weight fractions of the fibers. It has been established that, by strengthening natural rubber with this natural fiber, tear strength, hardness, and abrasion losses may be significantly increased. From the fabricated composite specimens, it was speculated that the composite exhibits the best desirable properties at a fiber length of $6 \mathrm{~mm}$. Furthermore, the introduction of higher fiber loadings, such as 30\% fibers per 100 parts rubber, also bears some interest in view of an improved hardness, although it conversely appears to seriously reduce tensile elongation. Critical issues appear in possible processing, especially in view of proposing the possible application of these composites wherever higher hardness is required, e.g., in brake shoes, vibration resistant screws, oil seals, and gaskets. The economic advantage obtained is due to the fact that phormium short fibers used for this purpose are obtained at no cost as waste from textile and especially rope manufacturing. Further evaluations could be centered on 
elucidating the combined effect of these fibers with different amounts of carbon black in a rubber compound and would need to include some analysis, such as that of the degree of swelling with different fuels.

Author Contributions: Conceptualization, S.P. and K.M.; methodology, S.P., K.M., and M.P.; investigation, S.P. and A.A.; writing - original draft preparation, S.P. and C.S.; writing-review and editing, C.S. and F.V.d.C.; supervision, N.R., F.V.d.C., and C.S. All authors have read and agreed to the published version of the manuscript.

Funding: This research received no external funding.

Data Availability Statement: All data are in the paper.

Conflicts of Interest: The authors declare no conflict of interest.

\section{References}

1. Saheb, D.N.; Jog, J.P. Natural fiber polymer composites: A review. Adv. Polym. Technol. 1999, 18, 351-363.

2. Bongarde, U.S.; Shinde, V.D. Review on natural fiber reinforcement polymer composites. Int. J. Eng. Sci. Innovat. Technol. 2014, $3,431-436$.

3. Tauqeer Ali, H.; Akrami, R.; Fotouhi, S.; Pashmforoush, F.; Fragassa, C.; Fotouhi, M. Effect of the stacking sequence on the impact response of carbon-glass/epoxy hybrid composites. FU Mech. Eng. 2020, 18, 69-77.

4. Bambach, M.R. Direct comparison of the structural compression characteristics of natural and synthetic fiber-epoxy composites: Flax, jute, hemp, glass and carbon fibers. Fibers 2020, 8, 62. [CrossRef]

5. De Paola, S.; Minak, G.; Fragassa, C.; Pavlovic, A. Green Composites: A Review of State of Art. In Proceedings of the 30th Danubia Adria Symposium on Advanced Mechanics, Croatian Society of Mechanics, Primosten, Croatia, 25-28 September 2013; pp. 77-78.

6. Hyseni, A.; De Paola, S.; Minak, G.; Fragassa, C. Mechanical Characterization of EcoComposites. In Proceedings of the 30th Danubia Adria Symposium on Advanced Mechanics, Croatian Society of Mechanics, Primosten, Croatia, 25-28 September 2013; pp. 175-176.

7. Pickering, K. (Ed.) Properties and Performance of Natural-Fibre Composites; Elsevier: Amsterdam, The Netherlands, 2008.

8. Fragassa, C.; Pavlovic, A.; Santulli, C. Mechanical and impact characterisation of flax and basalt fibre bio-vinylester composites and their hybrids. Compos. Part B 2018, 137, 247-259. [CrossRef]

9. Fragassa, C. Effect of Natural Fibers and Bio-Resins on Mechanical Properties in Hybrid and Non-Hybrid Composites. In Proceedings of the 8th Conference on Times of Polymers \& Composites: From Aerospace to Nanotechnology, Ischia, Italy, 19-23 June 2016; Volume 1736. [CrossRef]

10. Fairlie, G.; Njuguna, J. Damping properties of flax/carbon hybrid epoxy/fibre-reinforced composites for automotive semistructural applications. Fibers 2020, 8, 64. [CrossRef]

11. Lau, K.T.; Hung, P.Y.; Zhu, M.H.; Hui, D. Properties of natural fibre composites for structural engineering applications. Compos. Part B 2018, 136, 222-233. [CrossRef]

12. Zivkovic, I.; Pavlovic, A.; Fragassa, C. Improvements in wood thermoplastic composite materials properties by physical and chemical treatments. Int. J. Qual. Res. 2016, 10, 205-218.

13. Rattanasom, N.; Saowapark, T.; Deeprasertkul, C. Reinforcement of natural rubber with silica/carbon black hybrid filler. Polym. Test 2007, 26, 369-377. [CrossRef]

14. Masłowski, M.; Miedzianowska, J.; Strzelec, K. Natural rubber composites filled with crop residues as an alternative to vulcanizates with common fillers. Polymer 2019, 11, 972. [CrossRef]

15. Jacob, M.; Thomas, S.; Varughese, K.T. Mechanical properties of sisal/oil palm hybrid fiber reinforced natural rubber composites. Compos. Sci. Technol. 2004, 64, 955-965. [CrossRef]

16. Pantamanatsopa, P.; Ariyawiriyanan, W.; Meekeaw, T.; Suthamyong, R.; Arrub, K.; Hamada, H. Effect of modified jute fiber on mechanical properties of green rubber composite. Energy Procedia 2014, 56, 641-647. [CrossRef]

17. Geethamma, V.G.; Kalaprasad, G.; Groeninckx, G.; Thomas, S. Dynamic mechanical behavior of short coir fiber reinforced natural rubber composites. Compos. Part A 2005, 36, 1499-1506. [CrossRef]

18. Lopattananon, N.K.; Panawarangkul, K.; Sahakaro, K.; Ellis, B. Performance of pineapple leaf fiber-natural rubber composites: The effect of fiber surface treatments. J. Appl. Polym. Sci. 2006, 102, 1974-1984. [CrossRef]

19. Lovely, M.; Joseph, R. Mechanical properties of short isora fiber-reinforced natural rubber composites: Effects of fiber length, orientation, and loading; alkali treatment; and bonding agent. J. Appl. Polym. Sci. 2007, 103, 1640-1650.

20. Zarate, C.N.; Aranguren, M.I.; Reboredo, M.M. Influence of fiber volume fraction and aspect ratio in resol-Sisal composites. J. Appl. Polym. Sci. 2003, 89, 2714-2722. [CrossRef]

21. Chenal, J.M.; Gauthier, C.; Chazeau, L.; Guy, L.; Bomal, Y. Parameters governing strain induced crystallization in filled natural rubber. Polymer 2007, 48, 6893-6901. [CrossRef] 
22. Cruthers, N.M.; Carr, D.J.; Laing, R.M.; Niven, B.E. Structural differences among fibers from six cultivars of harakeke (Phormium Tenax, New Zealand flax). Text Res. J. 2006, 76, 601-606. [CrossRef]

23. Fortunati, E.; Puglia, D.; Monti, M.; Peponi, L.; Santulli, C.; Kenny, J.M.; Torre, L. Extraction of cellulose nanocrystals from Phormium tenax fibres. J. Polym. Environ. 2013, 21, 319-328. [CrossRef]

24. Di Giorgio, L.; Salgado, P.R.; Dufresne, A.; Mauri, A.N. Nanocelluloses from phormium (Phormium tenax) fibers. Cellulose 2020, 27, 4975-4990. [CrossRef]

25. Krause Sammartino, L.M.; Aranguren, M.I.; Reboredo, M. Chemical and mechanical characterization of two South American plant fibers for polymer reinforcement Caranday Palm and Phormium. J. Appl. Polym. Sci. 2010, 115, 2236-2245. [CrossRef]

26. De Rosa, I.M.; Kenny, J.M.; Puglia, D.; Santulli, C.; Sarasini, F. Tensile behavior of New Zealand Flax (Phormium tenax) fibers. J. Reinf. Plast. Compos. 2010, 29, 3450-3454. [CrossRef]

27. Le Guen, M.J.; Newman, R.H. Pulped Phormium Tenax leaf fibers as reinforcement for epoxy composites. Compos. Part A 2007, 38, 2109-2115. [CrossRef]

28. Newman, R.H.; Clauss, E.C.; Carpenter, J.E.P.; Thumm, A. Epoxy composites reinforced with deacetylated Phormium Tenax leaf fibers. Compos. Part A 2007, 38, 2164-2170. [CrossRef]

29. Newman, R.H.; Le Guen, M.J.; Battley, M.A.; Carpenter, J.E.P. Failure mechanisms in composites reinforced with unidirectional Phormium leaf fiber. Compos. Part A 2010, 41, 353-359. [CrossRef]

30. Puglia, D.; Santulli, C.; Sarasini, F.; Kenny, J.M.; Valente, T. Thermal and mechanical characterization of phormium tenax reinforced polypropylene composites. J. Thermoplast. Compos. Mater. 2014, 27, 1493-1503. [CrossRef]

31. De Rosa, I.M.; Iannoni, A.; Kenny, J.M.; Puglia, D.; Santulli, C.; Sarasini, F.; Terenzi, A. Poly(lactic acid)/phormium tenax composites: Morphology and thermo-mechanical behaviour. Polym. Compos. 2011, 32, 1362-1368. [CrossRef]

32. Muhammad Hijas, N.M.; Pramod, P.; Prasanth, P.; Sivam, H.; Sivasubramanian, P. Development of jute fibre reinforced natural rubber composite material \& determination of its mechanical properties. IJIRST 2017, 3, 207-212.

33. González, L.; Rodriguez, A.; Valentin, J.L.; Marcos-Fernández, A. Conventional and Efficient Crosslinking of Natural Rubber. KGK Rubberpoint 2005, 58, 638-646.

34. Jacob, M.; Varughese, K.T.; Thomas, S. Water sorption studies of hybrid biofiber-reinforced natural rubber biocomposites. Biomacromolecules 2005, 6, 2969-2979. [CrossRef]

35. Thomason, J.L.; Carruthers, J.; Kelly, J.; Johnson, G. Fibre cross-section determination and variability in sisal and flax and its effects on fibre performance characterisation. Compos. Sci. Technol. 2011, 71, 1008-1015. [CrossRef]

36. Charlet, K.; Baley, C.; Morvan, C.; Jernot, J.P.; Gomina, M.; Bréard, J. Characteristics of Hermès flax fibres as a function of their location in the stem and properties of the derived unidirectional composites. Compos. Part A 2007, 38, 1912-1921. [CrossRef]

37. De Rosa, I.M.; Santulli, C.; Sarasini, F. Mechanical and thermal characterization of epoxy composites reinforced with random and quasi-unidirectional untreated Phormium tenax leaf fibers. Mater. Des. 2010, 31, 2397-2405. [CrossRef]

38. Geethamma, V.G.; Mathew, K.T.; Lakshminarayanan, R.; Thomas, S. Composite of short coir fibres and natural rubber: Effect of chemical modification, loading and orientation of fibre. Polymer 1998, 39, 1483-1491. [CrossRef]

39. Barrera, C.S.; Cornish, K. Processing and mechanical properties of natural rubber/waste-derived nano filler composites compared to macro and micro filler composites. Ind. Crops Prod. 2017, 107, 217-231. [CrossRef]

40. Wongpreedee, T.; Amornsakchai, T. Synchrotron X-ray diffraction study of pineapple leaf fiber reinforced natural rubber composites during stretching. Suranaree J. Sci. Technol. 2015, 22, 253-263.

41. Naira, S.S.; Wang, S.; Hurley, D.C. Nanoscale characterization of natural fibers and their composites using contact-resonance force microscopy. Compos. Part A 2010, 41, 624-631. [CrossRef]

42. Alex, R.; De, P.P.; De, S.K. Self-vulcanizable rubber blend system based on epoxidized natural rubber and carboxylated nitrile rubber. J. Polym. Sci. Part. C 1989, 27, 361-367. [CrossRef]

43. Paul, K.T.; Pabi, S.K.; Chakraborty, K.K.; Nando, G.B. Nanostructured fly ash-styrene butadiene rubber hybrid nanocomposites. Polym. Compos. 2009, 30, 1647-1656. [CrossRef]

44. Rowell, R.M. A New Generation of Composite Materials from Agro-Based Fiber. In Polymers and Other Advanced Materials; Prasad, P.N., Mark, J.E., Fai, T.J., Eds.; Springer: Boston, MA, USA, 1995; pp. 659-665.

45. Jacob, M.; Thomas, S.; Varughese, K.T. Natural rubber composites reinforced with sisal/oil palm hybrid fibers: Tensile and cure characteristics. J. Appl. Polym. Sci. 2004, 93, 2305-2312. [CrossRef]

46. Raghavendra, S.; Shetty, P.B.; Mukunda, P.G. Mechanical properties of short banana fiber reinforced natural rubber composites. Int. J. Innov. Res. Sci. Eng. Technol. 2013, 2, 1652-1655.

47. Osabohien, E.; Egboh, S.H.O. Utilization of bowstring hemp fiber as a filler in natural rubber compounds. J. Appl. Polym. Sci. 2008, 107, 210-214. [CrossRef]

48. Stelescu, M.D.; Manail, E.; Craciun, G.; Dumitrascu, M. New green polymeric composites based on hemp and natural rubber processed by electron beam irradiation. Sci. World J. 2014, 2014, 684047. [CrossRef] [PubMed] 